Kontribusi Ilmu Pengetahuan, Oleh: Badrus

\title{
KONTRIBUSI ILMU PENGETAHUAN, FILSAFAT DAN AGAMA TERHADAP KEHIDUPAN MANUSIA
}

\author{
Badrus*
}

\begin{abstract}
Abstark
Ilmu pengetahuan, filsafat dan agama merupakan tiga unsur yang mengarahkan manusia dalam mencapai tujuan hidup. Sejarah ilmu pengetahuan manusia dari masa ke masa terus mengalami perubahan dan perkembangan. Filsafat bersamasama dengan seni, kepercayaan dan ilmu membentuk eksistensi manusiawi, sebagai suatu sistem yang saling berinteraksi. Agama menjadi pegangan umat manusia. Filsafat, sains dan agama mempunyai wilayah yang berbeda, namun ketiganya memberikan kontribusi yang besar terhadap kehidupan manusia.
\end{abstract}

Kata Kunci: Ilmu Pengetahuan, Filsafat, Agama

\section{Pendahuluan}

Ilmu pengetahuan terus berkembang, seiring dengan perkembangan manusia itu sendiri. Kontribusi ilmu pengetahuan bagi kehidupan manusia sangatlah besar, khususnya terhadap perkembangan pemikiran manusia. Dengan ilmu pengetahuan manusia dapat memiliki pandangan yang luas. Dengan ilmu pengetahuan manusia dapat memencahkan masalah. Dengan ilmu pengetahuan memudahkan manusia mencapai tujuan. Bahkan dengan ilmu pengetahuan manusia dapat memperoleh kebahagiaan dan kesejahteraan.

Walau pun demikian ilmu pengetahuan tidak satu-satunya yang memberikan kontribusi kepada manusia, tetapi di sana ada filsafat, dan agama juga tidak kecil kontribusinya terhadap kehidupan manusia. Bagaimana ketiga macam sumber pengetahuan itu memberikan kontribusi kepada manusia. Tulisan ini mencoba menjelaskan secara historis kontibusi ilmu pengetahuan, filsafat, dan agama terhadap kehidupan manusia.

\footnotetext{
* Dosen Tetap Institut Agama Islam Tribakti Kediri
}

Vol. 22 Nomor. 2 Juli 2011 
Kontribusi Ilmu Pengetahuan, Oleh: Badrus

\section{Ilmu Pengetahuan}

Menurut kamus Webster New World Dictionary, kata science berasal dari kata latin, scire yang artinya mengetahui. Secara bahasa science berarti "keadaan atau fakta dan sering diartikan sebagai pengetahuan (knowledge) yang dikontraskan dengan intuisi dan kepercayaan. Namun kata ini mengalami perkembangan dan perubahan makna, sehingga science berarti pengetahuan yang sistematis yang didapat melalui observasi, kajian, dan eksperimen yang dilakukan untuk menetukan sifat dasar atau prinsip-prinsip yang dikaji. Sedangkan dalam bahasa Arab, ilmu (ilm) berasal dari kata alima yang artinya mengetahui. Jadi ilmu secara harfiah tidak terlalu berbeda dengan science yang berasal dari kata scire. Namun ilmu memiliki ruang lingkup yang berbeda dengan science (sains). Sains hanya dibatasi pada bidang-bidang empiris-positivistik sedangkan ilmu melampauinya dengan non empiris seperti matematika dan metafisika (Kartanegara, 2003: 34).

\section{PERKEMBANGAN ILMU PENGETAHUAN}

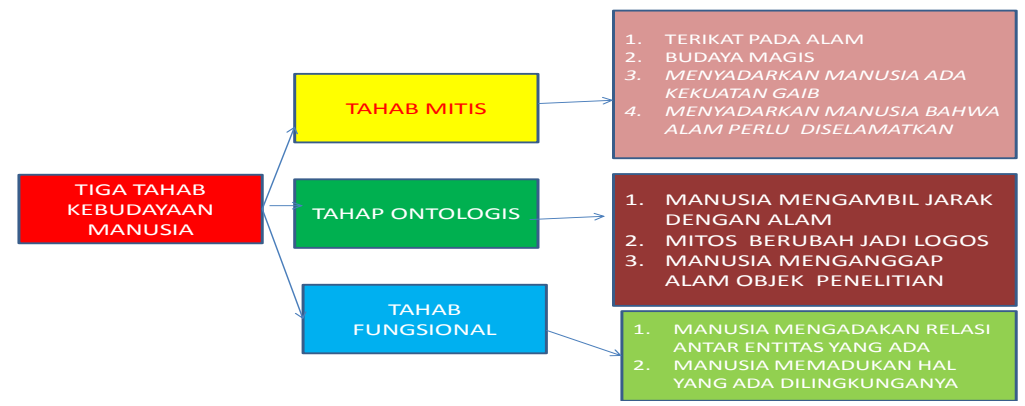

Selanjutnya dalam perkembangan ilmu pengetahuan Van Peurson mengemukakan bahwa dalam kebudayaan (baca kehidupan) manusia dapat dibedakan menjadi tiga tahap, yaitu tahap mitis, ontologis dan fungsional. Pada tahap mitis, manusia merasa dikelilingi oleh kekuatan-kekuatan gaib. Manusia merasa takut terhadap kejadiankejadian alam di luar kekuasaanya. Untuk mengatasi kehidupan semacam ini mereka banyak mengadakan upacara-upacara ritual dengan berbagai sesaji, sikhir, atau apa saja yang dianggap dapat melunakkan kehendak alam. Hal ini terlihat pada masyarakat primitive, dan pada masa ini tergolong masa pra-ilmu pengetahuan. Kontribusi pra-ilmu saat itu pada manusia adalah memberikan ketenangan hidup. Dengan 
menjalankan magis, mereka berupaya menghilangkan rasa takut yang menghantui dalam hidupnya. ${ }^{1}$

Kontribusi pengetahuan pada tahap kedua ini, memberikan dampak yang lebih riil terhadap kehidupan manusia. Secara bertahap permasalahan manusia bisa teratasi. Begitu juga keinginan-keinginan manusia untuk menelusuri pengetahuan yang lebih jauh dapat dicapai, seperti keinginan manusia mendaki bulan, mengadakan komunikasi antar benua dan lain sebagainya.

Tahap kedua, ontologis yaitu pada masa manusia sudah berganti pandangan. Manusia tidak lagi merasa dikelilingi oleh kekuatankekuatan gaib, tetapi manusia sudah berani membebaskan diri untuk meneliti segala hal, alam dan termasuk dirinya sendiri. Pada tahap ini berkembang filsafat, ilmu pengetahuan (sain), dan kemudian teknologi modern berkembang. Tahap ketiga adalah tahap fungsional, yaitu manusia tidak lagi terikat dengan alam, atau mengambil jarak dengan alam, akan tetapi manusia ingin mengadakan relasi-relasi baru, suatu pertautan atau pola kehidupan yang saling berakait. Pemikiran fungsional mempersoalkan hubungan, pertautan, dan relasi yang memperlancar perbuatan atau pola kehidupan. Sebagaimana bagan berikut:

Kemajuan Pengetahuan dalam Tahap Kebudayaan Mitis, Ontologis, dan Fungsional

\begin{tabular}{|c|c|c|}
\hline Tahap Mitis & Tahap Ontologis & Tahap Fungsional \\
\hline $\begin{array}{lr}\text { Manusi } & \text { terikat } \\
\text { oleh kekuatan } \\
\text { gaib: saat ini } \\
\text { berkembang } \\
\text { pengetahuan pra- } \\
\text { ilmu, pseudo } \\
\text { ilmu, dan praktek } \\
\text { magis }\end{array}$ & $\begin{array}{l}\text { Manusia } \\
\text { mengambil jarak } \\
\text { dengan alam: } \\
\text { berkembang ilmu } \\
\text { alam, ilmu-ilmu } \\
\text { baru yang otonom. } \\
\text { Berkembang } \\
\text { teknologi modern. }\end{array}$ & $\begin{array}{l}\text { Manusia mencari } \\
\text { hubungan, } \\
\text { mengkaitkan untuk } \\
\text { mendapatkan } \\
\text { fungsi baru. Yang } \\
\text { berkembang saat } \\
\text { itu etika fungsional } \\
\text { menjadi sentral. }\end{array}$ \\
\hline
\end{tabular}

\section{Filsafat}

1 Dimyati, Moh, Ilmu Pengetahuan, Perkembangan, Pengajaran dan Penelitian Ilmiah, (Malang: Laboratorium KTP, Jurusan Kurikulum dan Teknologi Pendidikan IKIP Malang, 1990), h. 306. 
Filsafat dalam bahasa Inggris, yaitu philosophy, adapun istilah filsafat berasal dari bahasa Yunani, philosophia, yang terdiri atas dua kata: philos (cinta) atau philia (persahabatan, tertarik kepada) dan shopia (hikmah, kebijaksanaan, pengetahuan, keterampilan, pengalaman praktis, inteligensi). Jadi secara etimologi, filsafat berarti cinta kebijaksanaan atau kebenaran. Plato menyebut Socrates sebagai philosophos (filosof) dalam pengertian pecinta kebijaksanaan. Kata falsafah merupakan arabisasi yang berarti pencarian yang dilakukan oleh para filosof. Dalam Kamus Besar Bahasa Indonesia, kata filsafat menunjukkan pengertian yang dimaksud, yaitu pengetahuan dan penyelidikan dengan akal budi mengenai hakikat segala yang ada, sebab asal dan hukumnya. Manusia filosofis adalah manusia yang memiliki kesadaran diri dan akal sebagaimana ia juga memiliki jiwa yang independen dan bersifat spiritual.

\section{Kontribusi filsafat terhadap manusia}

Sumbangan filsafat terhadap manusia yang cukup besar adalah pandangan filsafat terhadap eksistensi manusia. Menurut Kenneth Boulding bahwa manusia merupakan suatu sistem. Di mana manusia digambarkan mempunyai semua ciri-ciri yang dimiliki hewan, malah lebih jauh dari hewan. Kelebihan manusi adalah bersifat mobilitas yang selalu meningkat, perilaku teologis, kesadaran diri, pengembangan diri, dan penerimaan informasi menjadi gambaran pikir. Di samping itu kelebihan manusia memiliki ciri khas, yakni keinsafan dan kesadaran diri. Maksudnya manusia mempunyai sifat pantul diri atau instropeksi. Ia mengetahui bahwa ia; sedang susah atau bahagia, sedang lupa atau ingat, bahkan lebih rumit lagi ia juga mengetahui tentang waktu yang dihubungkan dengan kematian. (Kenneth Boulding, 1956: 197). Selanjutnya Laszlo juga mengungkapkan:

"To be a man is thus to have the almost unique opportunity of getting to know oneself and the world in which one lives. Our knowledge has made us increasingly autonomus in nature, and enable us to create the world of culture. It has freed us from many of the biological existence and given us license to determine our own evolution."

(Menjadi manusia adalah memiliki kesempatan yang hampir khas untuk mengetahui diri sendiri dan dunia di mana manusia hidup. Pengetahuan kita mermbuat kita semakin otonom dalam alam, dan memungkinkan kita menciptakan dunia kebudayaan. Hal ini telah membebaskan kita dari banyak ikatan eksistensi biologis dan memberikan kepada kita kekuasaan untuk menentukan perkembangan kita sendiri) 
Kesadaran diri tersebut selanjutnya akan membentuk budi manusia. Karena secara filsafati bahwa suatu budi dipandang sebagai substansi metafisis (lawan dari kebendaan) yang ada pada seseorang. Lebih dari itu, budi adalah diri atau subjek yang mencerap, mengingat, membayangkan, merasakan, menggambarkan, berfikir, berkehendak dan melakukan jenis kegiatan-kegiatan yang secara fungsional berhubungan dengan organisasi tubuh perseorangan.

\section{Empat Unsur Eksistensi Manusiawi Pembentuk Kebudayaan}

Di sini dapat disampaikan bahwa isi eksistensi manusiawi ialah suatu proses budi manusia. Yaitu dengan serangkaian kegiatan yang secara pasti terarah pada suatu tujuan atau cenderung menghasilkan sesuatu. Kegiatan ini sering disebut sebagai usaha manusia. Prof. Jose Ferrater Mora mengatakan bahwa di antara hasil-hasil kerohanian manusia yang besar ada empat hal, yaitu filsafat, agama, seni, dan ilmu. Liang Gie berpendapat bahwa empat unsure ini dimulai dari seni, kemudian

Seni adalah proses menciptakan suatu yang indah baik dari luar diri manusia maupun dari diri manusia itu sendiri seperti tari, puisi, lagi dan sebagainya. Erich Kahler mendefinisikan bahwa seni adalah "Art is human activity which explorers and hereby creates, new reality in a suprarational, visional manner and presents it symbolically or methaporically, a microcosmic whole signifying a macrocosmic whole" (seni adalah suatu kegiatan manusia yang menjelajahi dan dengan ini menciptakan realita baru dalam suatu cara yang diluar akal dan berdasarkan penglihatan sewrta menyajikan realita itu secara berlambang atau kiasan ssebagai sebuah kebulatan dunia kecil yang mencerminkan sbuah kebulatan dunia besar).

Eksistensi kedua adalah kepercayaan, yaitu proses meneriman dan merasa yakin terhadap adanya sesuatu yang tertinggi yang mempunyai atas alam semesta ini. Hasil dari kepercayaan-kepercayaan ini sebagian besar berupa agama-agama, meskipun kepercayaankepercayaan kecil lainnya dapat pula ditemukan.

Sementara filsafat yang merupakan eksistensi manusia yang ketiga, timbul sebagai kritik reflektif terhadap kepercayaan agama. Betrand Russell juga menyinggung bahwa filsafat merupakan hasil dari dua factor, pertama dari konsepsi-konsepsi keagamaan dan etis yang diwariskan, kedua dari jenis penyelidikan yang dapat disebut ilmiah. Filsafat tidak seperti halnya agama yang bersandar pada wahyu, ia 
bersandar pada akal manusia dan sebagian besar tertuju pada pencarian pengetahuan. Hasil dari filsafat adalah kearifan, asas-asas tujuan akhir, pemikiran yang sistematis, dan pandangan yang menyeluruh yang dapat dicakup dalam kata Yunani shopia yang dikenal sekarang pengetahuan filsafati.

Eksistensi manusia yang terakhir adalah ilmu, yaitu merupakan kegiatan menyelidiki oleh budi manusia dengan memakai methodmethode yang diatur dan dikontrol untuk memperoleh sekumpulan fakta yang spesifik atau pengetahuan yang tertentu. Menurut Russell, hasilhasil dari kegiatan para ilmuwan adalah asas-asas, sistem-sistem, teoriteori, kaidah-kaidah, yang secara singkat dapat dinamakan ilmu pengetahuan ilmiah. Eksistensi manusia dalam bentuk struktur yang saling berhubungan dapat digambarkan membentuk persegi empat yang saling berhubungan di antara empat unsure.

\section{Empat Unsur Eksistensi Manusia}

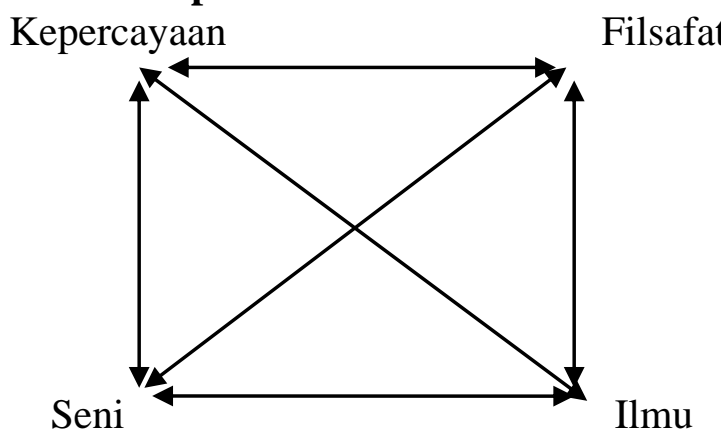

Dari unsur-unsur eksistensi manusia tersebut manusia dapat membentuk apa yang disebut kebudayaan. Menurut Koentjoro Ningrat, bahwa ada tiga macam hal yang dapat dikatakan kebudayaan. Pertama, berbentuk ide-ide atau gagasan-gagasan. Hal ini bisa berupa konsepkonsep yang telah dibukukan oleh ilmuwan, cendekiawan, dan siapa saja yang dapat menuangkan dalam bentuk tulisan. Kedua, berbentuk perilaku manusia. Pada tataran ini bisa berupa kebiasaan, keterampilan, cara-cara berkomuniakasi, cara menghormat, teknik-teknik menggunakan teknologi, dan aneka kesenian yang dilakukan manusia. Ketiga, berbentuk hasil karya manusia. Di sini bisa berbentuk bangunan-bangunan, tata ruang kota, alat-alat komunikasi, transpotasi, alat perekomian, kedokteran dan lain sebagainya. 
Kontribusi Ilmu Pengetahuan, Oleh: Badrus

\section{Agama}

Agama dalam tinjauan filsafat adalah suatu gejala yang luas dan rumit dan ada begitu banyak teori antropologis, sosiologis, psikologis, naturalitstik dan keagamaan tentang sifat dasar agama sehingga akibatnya tidak ada definisi yang diterima secara universal benar. Tetapi para filosuf telah mencatat cirri-ciri yang menentukan dari agama sebagaimana dilakukan oleh Alston. Menurut beliau ada Sembilan sifat khas agama:

1. Kepercayaan kepada hal-hal gaib

2. Perbedaan antara objek-objek yang suci dan yang duniawi

3. Tindakan-tindakan upacara yang dipusatkan pada objek-objek yang suci

4. Kode moral yang dipercayai dikuatkan oleh wahyu (Tuhan)

5. Perasaan-perasaan keagamaan secara khusus (taat, rasa rahasia, rasa bersalah, pemujaan) yang timbul dihadapan objek-objek yang suci dan selama tindakan-tindakan upacara

6. Adanya doa kepada Tuhannya

7. Suatu pandangan dunia (suatu pandangan umum mengenai dunia sebagai suatu keseluruhan dan tempat perseorangan di dalamnya

8. Suatu organisasi yang kurang lebih menyeluruh tentang kehidupan seorang berdasar pada pandangan dunia itu

9. Suatu kelompok social yang diikat bersama oleh delapan sifat di atas.

Fungsi filsafat terhadap agama atau katakanlah filsafat agama bukanlah mengadakan pembelaan terhadap keyakinan-keyaninan keagamaan, tetapi pemikiran filsafati tentang agama, yaitu suatu pemeriksaan yang reflektif kritis dan analisis tentang arti-arti dan kepercayaan yang terlibat dalam agama. ${ }^{2}$

\section{PENGETAHUAN MANUSIA}

\begin{tabular}{|l|l|l|l|l|}
\hline Pengetahuan & \multicolumn{1}{|c|}{ Obyek } & Paradigma & Metode & Kriteria \\
\hline Sains & Empiris & Sains & $\begin{array}{l}\text { Metode } \\
\text { Ilmiah }\end{array}$ & $\begin{array}{l}\text { Rasional } \\
\text { empiris }\end{array}$ \\
\hline Filsafat & Abstrak & Rasional & $\begin{array}{l}\text { Metode } \\
\text { rasional }\end{array}$ & Rasional \\
\hline
\end{tabular}

${ }^{2}$ Yervant H. krikorian, The Philosopy of Religion: Introduction dalam Bronstein, et al, eds, Basic Problem of Philosopy, 1999), h. 24

Vol. 22 Nomor. 2 Juli 2011 
Kontribusi Ilmu Pengetahuan, Oleh: Badrus

\begin{tabular}{|l|l|l|l|l|}
\hline Mistis & $\begin{array}{l}\text { Abstark } \\
\text { suprarasional }\end{array}$ & Mistis & $\begin{array}{l}\text { Latihan } \\
\text { percaya }\end{array}$ & $\begin{array}{l}\text { Rasa, } \\
\text { iman, } \\
\text { logis, } \\
\text { kadang } \\
\text { empiris }\end{array}$ \\
\hline
\end{tabular}

\section{Kontribusi Agama terhadap Kehidupan Manuisia}

Kontribusi agama terhadap kehidupan manusia berbeda dengan filsafat dan ilmu pengetahuan. Bila ilmu telah berhasil menolong manusia untuk memecahkan masalah dengan berbagai penelitiannya, agama memberikan jawaban terhadap segala hal yang tidak dapat ditembus oleh filsafat dan ilmu. Pertanyaan seperti "untuk apa hidup ini, akan kemana hidup ini, bagaimana bumi mulanya terjadi, siapakah Tuhan itu, bagaimana manusia setelah mati, dan seterusnya" Ini semua yang dapat menjawab adalah agama. Di samping itu agama mengarahkan ilmu yang dibentuk dari rasio dan dari hasil pengamtan dan penelitian agar dapat digunakan dengan sebaik-baiknya. Ilmu dipandang dari kacamata agama adalah mengemban misi untuk mencapai kesejahteraan manusia baik di dunia maupun di akhirat kelak. $^{3}$

Posisi ilmu yang dimiliki manusia diperankan sebagai media untuk melakukan terobosan-terobosan pemikiran, penajamanpenajaman gagasan, perenungan-perenungan terhadap kejadian alam, baik yang berbentuk eksak maupun sosial. Sedangkan agama (keimanan) diposisikan pemberi bimbingan dan pengarahan terhadap sesuatu yang ingin dituju pengembaraan intelek Betapapun intelek diberi kesempatan untuk melakukan pengembaraan penalaran secara maksimal, tetapi dalam batas-batas yang dapat dikontrol oleh keimanan terhadap kekuasaan Tuhan (Allah swt), sehingga dapat menghasilkan ilmu pengetahuan yang memberi kesadaran manusia untuk mengetahui jati dirinya sendiri. Yaitu suatu identitas diri yang tetap sebagai hamba Tuhan yang diberikan kepercayaan untuk berkreasi.

\section{Kesimpulan}

1. Sejarah ilmu pengetahuan manusia dari masa ke masa terus mengalmi perubahan dan perkembangan. Karena itu sudah

3 Mujamil, Qomar, Epistimologi Pendidikan Islam dari Metode Rasional hingga Metode Kritik, (Jakarta: Erlangga, 2005), h. 112 
seharusnya kita selaku ilmuwan mengadakan inovasi di berbagai bidang ilmu pengetahuan, untuk memberikan kontribusi kepada kehidupan manusia.

2. Filsafat bersama-sama dengan seni, kepercayaan dan ilmu membentuk eksistensi manusiawi, sebagai suatu sistem yang saling berinteraksi.

3. Filsafat, sains dan agama mempunyai wilayah yang berbeda, namun ketiganya memberikan kontribusi yang besar terhadap kehidupan manusia. Filsafat berperan membentuk pemikiran yang sistematis dan arif, sains memberikan kemudahan dalam memecahkan masalah manusia, kemudian agama memberikan jawaban yang meyakinkan yang tidak dapat dipecahkan oleh filsafat maupun ilmu pengetahuan. 


\section{Daftar Pustaka}

Dimyati, Moh, Ilmu Pengetahuan, Perkembangan, Pengajaran dan Penelitian Ilmiah, Malang: Laboratorium KTP, Jurusan Kurikulum dan Teknologi Pendidikan IKIP Malang, 1990

Elvin, Laszlo, The system view of the World: The Natural Philosophy of the New Development in the Sciences, 1972

Gie,The Liang Suatu Konsepsi ke arah Penertiban bidang Filsafat, Yogyakarta: Karya Kencana, 1977

Mujamil, Qomar, Epistimologi Pendidikan Islam dari Metode Rasional hingga Metode Kritik, Jakarta: Erlangga, 2005

Yervant H. krikorian, The Philosopy of Religion: Introduction dalam Bronstein, et al, eds, Basic Problem of Philosopy, 1999. 